\title{
Design, Synthesis, and Evaluation of Ribose-Modified Anilinopyrimidine Derivatives as EGFR Tyrosine Kinase Inhibitors
}

\author{
Xiuqin Hu ${ }^{1}$, Disha Wang ${ }^{1}$, Yi Tong ${ }^{1}$, Linjiang Tong ${ }^{2}$, Xia Wang ${ }^{1}$, Lili Zhu ${ }^{1}$, Hua Xie ${ }^{2}$, \\ Shiliang $\mathrm{Li}^{1}$, You Yang ${ }^{1 *}$ and Yufang $\mathrm{Xu}^{1 *}$ \\ 'Shanghai Key Laboratory of New Drug Design, School of Pharmacy, East China University of Science and Technology, \\ Shanghai, China, ${ }^{2}$ Division of Anti-tumor Pharmacology, State Key Laboratory of Drug Research, Shanghai Institute of \\ Materia Medica, Chinese Academy of Sciences, Shanghai, China
}

OPEN ACCESS

Edited by:

Daniela Schuster,

University of Innsbruck, Austria

Reviewed by:

Johannes Kirchmair,

University of Hamburg, Germany

Dharmendra Kumar Yadav

All India Institute of Medical Sciences

Jodhpur, India

*Correspondence:

You Yang

yangyou@ecust.edu.cn

Yufang $X u$

yfxu@ecust.edu.cn

Specialty section:

This article was submitted to

Medicinal and Pharmaceutical

Chemistry,

a section of the journal

Frontiers in Chemistry

Received: 02 September 2017

Accepted: 30 October 2017

Published: 15 November 2017

Citation:

Hu X, Wang $D$, Tong $Y$, Tong $L$, Wang $X$, Zhu L, Xie H, Li S, Yang Y and Xu Y (2017) Design, Synthesis, and Evaluation of Ribose-Modified Anilinopyrimidine Derivatives as EGFR

Tyrosine Kinase Inhibitors.

Front. Chem. 5:101

doi: 10.3389/fchem.2017.00101
The synthesis of a series of ribose-modified anilinopyrimidine derivatives was efficiently achieved by utilizing DBU or tBuOLi-promoted coupling of ribosyl alcohols with 2,4,5-trichloropyrimidine as key step. Preliminary biological evaluation of this type of compounds as new EGFR tyrosine kinase inhibitors for combating EGFR L858R/T790M mutant associated with drug resistance in the treatment of non-small cell lung cancer revealed that 3- $\mathrm{N}$-acryloyl-5-O-anilinopyrimidine ribose derivative $\mathbf{1 a}$ possessed potent and specific inhibitory activity against EGFR L858R/T790M over WT EGFR. Based upon molecular docking studies of the binding mode between compound 1a and EGFR, the distance between the Michael receptor and the pyrimidine scaffold is considered as an important factor for the inhibitory potency and future design of selective EGFR tyrosine kinase inhibitors against EGFR L858R/T790M mutants.

Keywords: EGFR, tyrosine kinase inhibitors, anilinopyrimidine, glycosides, carbohydrate-based drugs

\section{INTRODUCTION}

Epidermal growth factor receptor (EGFR), a transmembrane protein with tyrosine kinase activity, is essential for cell growth, differentiation, migration, adhesion, and proliferation under normal physiological conditions (Gschwind et al., 2004). However, overexpression of EGFR has been associated with tumor growth and progression in a variety of cancers including non-small cell lung cancer (NSCLC), head and neck squamous cell carcinoma, and pancreatic cancer (Huang and Harari, 1999; Kris et al., 2003; Moore et al., 2007; Harrington et al., 2009). Therefore, regulation of EGFR has been deemed as an important strategy for the development of cancer therapy (Huang and Harari, 1999; Gschwind et al., 2004; Steuer et al., 2015).

First-generation EGFR tyrosine kinase inhibitors (TKIs) such as gefitinib and erlotinib that possess a 4-anilinoquinazoline scaffold, reversibly inhibit EGFR mutants (L858R and delE746_A750) as well as wild-type (WT) EGFR, resulting in significant disease control of patients with NSCLC (Figure 1) (Cohen et al., 2005; Cheng et al., 2016). However, drug resistance driven by activating mutation of the gatekeeper T790M residue in which the threonine group is replaced with the methionine moiety, greatly counteracted the clinical efficiency of first-generation TKIs against NSCLC (Ozvegy-Laczka et al., 2005; Balak et al., 2006; De Luca et al., 2008; Pao and Chmielecki, 2010). To address this issue, the irreversible EGFR TKIs (afatinib, osimertinib, WZ4002, and CO-1686) which contain a Michael acceptor moiety for binding covalently to the thiol group of 
<smiles>COc1cc2ncnc(Nc3ccc(F)c(Cl)c3)c2cc1OCCCN1CCOCC1</smiles>

Gefitinib

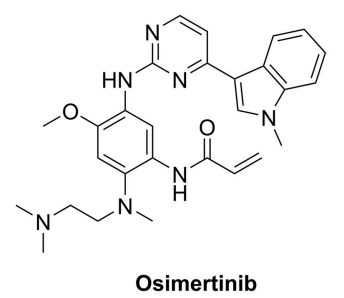

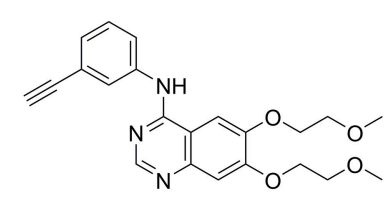

Erlotinib

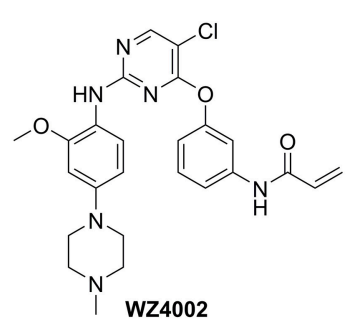

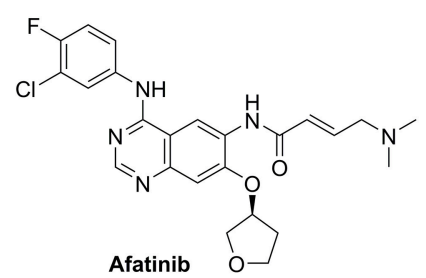

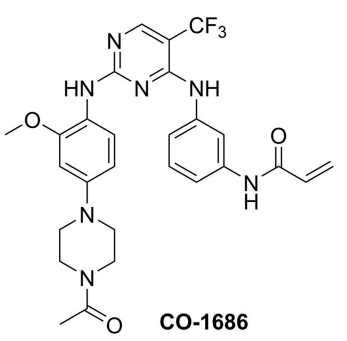

FIGURE 1 | Structures of three generations of EGFR tyrosine kinase inhibitors.

Cys797 in the ATP binding domain of EGFR, were developed to treat NSCLC via the efficient inhibition of EGFR mutants (Figure 1; Castellanos and Horn, 2015). Among them, secondgeneration TKIs such as afatinib potently inhibited both EGFR mutants (L858R/T790M) and WT-EGFR without mutant selectivity, thereby leading to side effects such as rash and diarrhea (Dungo and Keating, 2013). In contrast, thirdgeneration TKIs such as osimertinib, WZ4002, and CO-1686 bearing an anilinopyrimidine core, showed high potency and selectivity for EGFR L858R/T790M over WT EGFR, therefore serving as mutant-selective TKIs targeting EGFR mutants involved in NSCLC (Zhou et al., 2009; Walter et al., 2013; Cross et al., 2014; Finlay et al., 2014; Gray and Haura, 2014).

Considering the drug resistance is rapidly emerging for third-generation TKIs (Eberlein et al., 2015; Niederst et al., 2015; Piotrowska et al., 2015; Thress et al., 2015), design of EGFR inhibitors with new structural skeletons could lead to the discovery of novel types of TKIs against EGFR mutants such as the triple mutant L858R/T790M/C797S (Günther et al., 2016, 2017; Jia et al., 2016; Juchum et al., 2017; Park et al., 2017). Based on the fact that most commercially available TKIs are ATP-competitive inhibitors for binding at the catalytic domain of the EGFR tyrosine kinase (Traxler and Furet, 1999; Grünwald and Hidalgo, 2003; Normanno et al., 2003), we envisioned that replacement of the phenyl ring on the right side of WZ4002 with a chiral ribosyl moiety would provide compound $\mathbf{1}$ as a novel type of carbohydrate-based EGFR TKI against the drug resistance involved in NSCLC (Figure 2). Here we report the synthesis, preliminary biological evaluation and molecular docking studies of ribose-containing anilinopyrimidine derivatives as EGFR TKIs against EGFR L858R/T790M.

\section{MATERIALS AND METHODS}

Commercial reagents were used without further purification except where noted. Solvents were dried and redistilled prior to use in the usual way. All reactions were performed in ovendried glassware with magnetic stirring under an inert atmosphere unless noted otherwise. Analytical thin layer chromatography (TLC) was performed on precoated plates of Silica Gel (0.25$0.3 \mathrm{~mm}$, Shanghai, China). The TLC plates were visualized with UV light and by staining with sulfuric acid-ethanol solution. Silica gel column chromatography was performed on Silica Gel AR (100-200 mesh, Shanghai, China). NMR spectra were measured with a Bruker Avance III 400 or Bruker Avance III 500 spectrometer. The ${ }^{1} \mathrm{H}$ and ${ }^{13} \mathrm{C}$ NMR spectra were calibrated against the residual proton and carbon signals of the solvents as internal references $\left(\mathrm{CDCl}_{3}: \delta_{\mathrm{H}}=7.26 \mathrm{ppm}\right.$ and $\delta_{\mathrm{C}}=77.2 \mathrm{ppm}$; $\mathrm{CD}_{3} \mathrm{OD}: \delta_{\mathrm{H}}=3.31 \mathrm{ppm}$ and $\left.\delta_{\mathrm{C}}=49.0 \mathrm{ppm}\right)$. Multiplicities are quoted as singlet (s), broad singlet (br s), doublet (d), doublet of doublets (dd), triplet $(\mathrm{t})$, or multiplet $(\mathrm{m})$. All NMR chemical shifts $(\delta)$ were recorded in ppm and coupling constants $(J)$ were reported in $\mathrm{Hz}$. Mass spectra were recorded on an Agilent Technologies 6120 or LCT Premier XE FTMS instrument.

\section{1,2-O-Isopropylidene-3- $\mathrm{N}$-acryloyl-3- deoxy-5-0-(2,5-dichloropyrimidin-4-yl)- $\alpha-$ D-ribofuranoside 7}

To a solution of compound $5(0.60 \mathrm{~g}, 2.47 \mathrm{mmol})$ in anhydrous $\mathrm{CH}_{2} \mathrm{Cl}_{2}(30 \mathrm{~mL})$ at room temperature, was added DBU $(1.48 \mathrm{~mL}$, $5.94 \mathrm{mmol})$ and 2,4,5-trichloropyrimidine $6(0.57 \mathrm{~mL}, 4.94$ $\mathrm{mmol})$. After stirring at room temperature for $2 \mathrm{~h}$, the reaction mixture was diluted with saturated aqueous $\mathrm{NH}_{4} \mathrm{Cl}$, and extracted with $\mathrm{CH}_{2} \mathrm{Cl}_{2}$. The organic layer was washed with brine, dried over $\mathrm{Na}_{2} \mathrm{SO}_{4}$, and concentrated in vacuo. The residue was purified by silica gel chromatography (petroleum ether/EtOAc: 80/1) to give $7(0.88 \mathrm{~g}, 92 \%)$ as a pale yellow syrup: ${ }^{1} \mathrm{H}$ NMR (400 $\left.\mathrm{MHz}, \mathrm{CDCl}_{3}\right) \delta 8.30(\mathrm{~s}, 1 \mathrm{H}), 6.29(\mathrm{dd}, J=1.2,17.2 \mathrm{~Hz}, 1 \mathrm{H}), 6.12$ $(\mathrm{dd}, J=10.4,17.2 \mathrm{~Hz}, 1 \mathrm{H}), 6.07(\mathrm{~d}, J=8.8 \mathrm{~Hz}, 1 \mathrm{H}, \mathrm{NH}), 5.90(\mathrm{~d}$, $J=3.6 \mathrm{~Hz}, 1 \mathrm{H}, \mathrm{H}-1), 5.69(\mathrm{dd}, J=1.2,10.4 \mathrm{~Hz}, 1 \mathrm{H}), 4.73(\mathrm{dd}$, $J=2.4,12.0 \mathrm{~Hz}, 1 \mathrm{H}), 4.66(\mathrm{t}, J=4.0 \mathrm{~Hz}, 1 \mathrm{H}), 4.61-4.55(\mathrm{~m}, 2 \mathrm{H})$, 


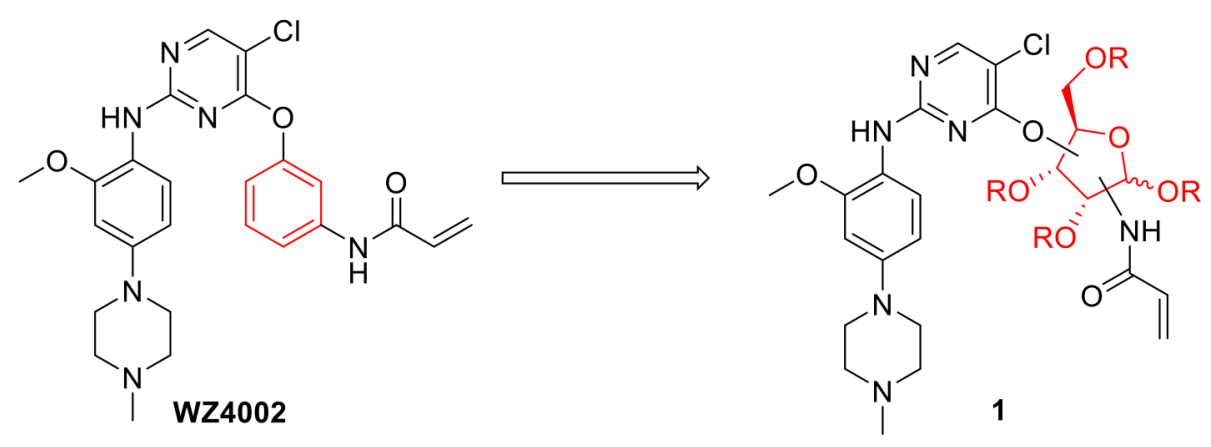

FIGURE 2 | Design of novel EGFR tyrosine kinase inhibitors.

$4.16(\mathrm{~m}, 1 \mathrm{H}), 1.57$ (s, $3 \mathrm{H}), 1.35$ (s, $3 \mathrm{H}) ;{ }^{13} \mathrm{C}$ NMR $(100 \mathrm{MHz}$, $\left.\mathrm{CDCl}_{3}\right) \delta 165.4,165.3,157.4,157.2,130.1,128.0,117.0,113.0$, 104.7, 79.1, 78.2, 67.3, 52.1, 26.8, 26.5; ESI-MS (ESI) m/z calcd for $\mathrm{C}_{15} \mathrm{H}_{17} \mathrm{O}_{5} \mathrm{~N}_{3} \mathrm{Cl}_{2} \mathrm{Na}[\mathrm{M}+\mathrm{Na}]^{+}$412.0, found 412.0.

\section{1,2-O-Isopropylidene-3-N-acryloyl-3- deoxy-5-O-[5-chloro-2-N-(2-methoxy-4-(4- methylpiperazin-1-yl)phenyl)pyrimidin-4- \\ yl]- $\alpha$-D-ribofuranoside 1a}

To a solution of compound $7(80 \mathrm{mg}, 0.21 \mathrm{mmol})$ and aniline derivative 8 (91 $\mathrm{mg}, 0.41 \mathrm{mmol})$ in isobutanol $(3 \mathrm{~mL})$, was added TFA $(0.12 \mathrm{~mL}, 1.55 \mathrm{mmol})$. The mixture was heated to $100^{\circ} \mathrm{C}$ and stirred for $5 \mathrm{~h}$. After cooling down to room temperature, the mixture was quenched with $\mathrm{Et}_{3} \mathrm{~N}(3 \mathrm{~mL})$ and concentrated in vacuo to give a residue, which was purified by silica gel column chromatography $\left(\mathrm{CH}_{2} \mathrm{Cl}_{2} / \mathrm{MeOH}: 30 / 1\right)$ to give $\mathbf{1 a}(82 \mathrm{mg}, 69 \%)$ as a pale yellow powder: ${ }^{1} \mathrm{H} \mathrm{NMR}\left(400 \mathrm{MHz}, \mathrm{CDCl}_{3}\right) \delta 8.10(\mathrm{~d}$, $J=8.8 \mathrm{~Hz}, 1 \mathrm{H}), 8.08(\mathrm{~s}, 1 \mathrm{H}), 7.35$ (br s, $1 \mathrm{H}), 6.56(\mathrm{dd}, J=2.4$, $8.8 \mathrm{~Hz}, 1 \mathrm{H}), 6.52$ (d-like, $J=2.4 \mathrm{~Hz}, 1 \mathrm{H}), 6.30(\mathrm{dd}, J=1.2$, $17.2 \mathrm{~Hz}, 1 \mathrm{H}), 6.11(\mathrm{~m}, 2 \mathrm{H}), 5.91(\mathrm{~d}, J=3.6 \mathrm{~Hz}, 1 \mathrm{H}, \mathrm{H}-1), 5.67$ (dd, $J=1.2,10.4 \mathrm{~Hz}, 1 \mathrm{H}), 4.66(\mathrm{~m}, 2 \mathrm{H}), 4.59-4.49(\mathrm{~m}, 3 \mathrm{H}), 4.22$ (m, $1 \mathrm{H}), 3.86(\mathrm{~s}, 3 \mathrm{H}), 3.16$ (t-like, $J=5.2 \mathrm{~Hz}, 4 \mathrm{H}), 2.58$ (t-like, $J=5.2 \mathrm{~Hz}, 4 \mathrm{H}), 2.34(\mathrm{~s}, 3 \mathrm{H}), 1.58(\mathrm{~s}, 3 \mathrm{H}), 1.35(\mathrm{~s}, 3 \mathrm{H}) ;{ }^{13} \mathrm{C}$ NMR $\left(100 \mathrm{MHz}, \mathrm{CDCl}_{3}\right) \delta 165.4,164.1,157.9,156.5,149.2,147.5$, $130.2,127.8,122.0,120.0,112.9,108.3,106.2,104.8,100.6,79.1$, 78.2, 66.6, 55.8, 55.3, 52.7, 50.2, 46.2, 26.8, 26.5; HRMS (ESI) m/z calcd for $\mathrm{C}_{27} \mathrm{H}_{36} \mathrm{O}_{6} \mathrm{~N}_{6} \mathrm{ClNa}[\mathrm{M}+\mathrm{H}]^{+}$575.2385, found 575.2385.

\section{3-N-Acryloyl-3-deoxy-5-O-[5-chloro-2- N- (2-methoxy-4-(4-methylpiperazin-1- yl)phenyl)pyrimidin-4-yl]-D-ribofuranose 1b} A solution of compound 1a (58 mg, $0.10 \mathrm{mmol})$ in TFA/acetic acid/water $(1 / 15 / 4, \mathrm{v} / \mathrm{v} / \mathrm{v}, 5 \mathrm{~mL})$ was stirred at $70^{\circ} \mathrm{C}$ for $7 \mathrm{~h}$. Concentration in vacuo and elution through reverse phase C18 column $\left(\mathrm{H}_{2} \mathrm{O} / \mathrm{MeOH}: 2 / 3\right)$ provided $\mathbf{1 b}(44 \mathrm{mg}, 83 \%)$ as a pale yellow syrup: ${ }^{1} \mathrm{H}$ NMR $\left(400 \mathrm{MHz}, \mathrm{CD}_{3} \mathrm{OD}\right) \delta 8.07$ (s, $1 \mathrm{H}), 8.05$ (s, $2.4 \mathrm{H}), 7.92(\mathrm{~m}, 3.4 \mathrm{H}), 6.67$ (d-like, $J=2.4 \mathrm{~Hz}$, $3.4 \mathrm{H}), 6.58(\mathrm{dd}, J=2.8,8.8 \mathrm{~Hz}, 3.4 \mathrm{H}), 6.35(\mathrm{~m}, 3.4 \mathrm{H}), 6.21(\mathrm{~m}$, $3.4 \mathrm{H}), 5.67(\mathrm{~m}, 3.4 \mathrm{H}), 5.38(\mathrm{~d}, J=4.0 \mathrm{~Hz}, 1 \mathrm{H}), 5.22(\mathrm{~s}, 2.4 \mathrm{H})$, $4.67(\mathrm{~m}, 2.4 \mathrm{H}), 4.58(\mathrm{~m}, 3.4 \mathrm{H}), 4.49(\mathrm{~m}, 4.4 \mathrm{H}), 4.34-4.24(\mathrm{~m}$,
$4.4 \mathrm{H}), 4.00$ (d-like, $J=4.4 \mathrm{~Hz}, 2.4 \mathrm{H}), 3.87(\mathrm{~s}, 10.2 \mathrm{H}), 3.78(\mathrm{~m}$, $6.8 \mathrm{H}), 3.58(\mathrm{~m}, 6.8 \mathrm{H}), 3.26(\mathrm{~m}, 6.8 \mathrm{H}), 3.03(\mathrm{~m}, 6.8 \mathrm{H}), 2.96(\mathrm{~s}$, $10.2 \mathrm{H}$ ); HRMS (ESI) m/z calcd for $\mathrm{C}_{24} \mathrm{H}_{32} \mathrm{O}_{6} \mathrm{~N}_{6} \mathrm{ClNa}[\mathrm{M}+\mathrm{H}]^{+}$ 535.2072 , found 535.2079 .

\section{2,3-O-Isopropylidene-5-0-(2,5- dichloropyrimidin-4-yl)- $\alpha$-D-ribofuranosyl acrylamide 14}

To a solution of compound $13(147 \mathrm{mg}, 0.60 \mathrm{mmol})$ in anhydrous $\mathrm{CH}_{2} \mathrm{Cl}_{2}(25 \mathrm{~mL})$ at room temperature, was added DBU $(0.21 \mathrm{~mL}, 1.42 \mathrm{mmol})$ and 2,4,5-trichloropyrimidine 6 $(0.12 \mathrm{~mL}, 1.07 \mathrm{mmol})$. After stirring at room temperature for $2 \mathrm{~h}$, the reaction mixture was diluted with saturated aqueous $\mathrm{NH}_{4} \mathrm{Cl}$, and extracted with $\mathrm{CH}_{2} \mathrm{Cl}_{2}$. The organic layer was washed with brine, dried over $\mathrm{Na}_{2} \mathrm{SO}_{4}$, and concentrated in vacuo. The residue was purified by silica gel chromatography (petroleum ether/EtOAc: $5 / 1)$ to give $\mathbf{1 4}(217 \mathrm{mg}, 93 \%)$ as a colorless syrup: ${ }^{1} \mathrm{H} \mathrm{NMR}\left(400 \mathrm{MHz}, \mathrm{CDCl}_{3}\right) \delta 8.36(\mathrm{~s}, 1 \mathrm{H}), 6.58(\mathrm{~d}, J=9.2 \mathrm{~Hz}$, $1 \mathrm{H}, \mathrm{NH}), 6.32(\mathrm{dd}, J=1.2,17.2 \mathrm{~Hz}, 1 \mathrm{H}), 6.15(\mathrm{dd}, J=10.4$, $17.2 \mathrm{~Hz}, 1 \mathrm{H}), 6.08(\mathrm{dd}, J=4.0,9.2 \mathrm{~Hz}, 1 \mathrm{H}, \mathrm{H}-1), 5.72(\mathrm{dd}$, $J=1.2,10.4 \mathrm{~Hz}, 1 \mathrm{H}), 4.86($ d-like, $J=6.0 \mathrm{~Hz}, 1 \mathrm{H}), 4.82(\mathrm{dd}$, $J=4.4,6.0 \mathrm{~Hz}, 1 \mathrm{H}), 4.55(\mathrm{~m}, 2 \mathrm{H}), 4.45(\mathrm{t}, J=2.8 \mathrm{~Hz}, 1 \mathrm{H}), 1.57$ $(\mathrm{s}, 3 \mathrm{H}), 1.38(\mathrm{~s}, 3 \mathrm{H}) ;{ }^{13} \mathrm{C} \mathrm{NMR}\left(100 \mathrm{MHz}, \mathrm{CDCl}_{3}\right) \delta$ 165.1, 165.0, 157.7, 157.4, 130.6, 128.2, 116.8, 113.4, 82.3, 81.6, 79.7, 79.4, 70.4, 26.4, 24.8; HRMS (ESI) m/z calcd for $\mathrm{C}_{15} \mathrm{H}_{17} \mathrm{O}_{5} \mathrm{~N}_{3} \mathrm{Cl}_{2} \mathrm{Na}[\mathrm{M}+$ $\mathrm{Na}]^{+}$412.0443, found 412.0448 .

\section{5-O-[5-Chloro-2-N-(2-methoxy-4-(4- methylpiperazin-1-yl)phenyl)pyrimidin-4- yl]-D-ribofuranosyl acrylamide 1c}

To a solution of compound $\mathbf{1 4}(58 \mathrm{mg}, 0.15 \mathrm{mmol})$ and aniline derivative 8 ( $66 \mathrm{mg}, 0.30 \mathrm{mmol})$ in isobutanol $(3 \mathrm{~mL})$, was added TFA $(0.084 \mathrm{~mL}, 1.13 \mathrm{mmol})$. The mixture was heated to $100^{\circ} \mathrm{C}$ and stirred for $5 \mathrm{~h}$. After cooling down to room temperature, the mixture was quenched with $\mathrm{Et}_{3} \mathrm{~N}(3 \mathrm{~mL})$ and concentrated in vacuo to give a residue, which was purified by silica gel column chromatography $\left(\mathrm{CH}_{2} \mathrm{Cl}_{2} / \mathrm{MeOH}\right.$ : 30/1) to give 15 (60 mg, 70\%) as a pale yellow oil: HRMS (ESI) m/z calcd for $\mathrm{C}_{27} \mathrm{H}_{36} \mathrm{O}_{6} \mathrm{~N}_{6} \mathrm{Cl}$ $[\mathrm{M}+\mathrm{H}]^{+} 575.2385$, found 575.2383. A solution of compound 
15 (85 mg, $0.15 \mathrm{mmol})$ in TFA/acetic acid/water (1/20/4, v/v/v, $4 \mathrm{~mL}$ ) was stirred at $50^{\circ} \mathrm{C}$ for $5 \mathrm{~h}$. Concentration in vacuo and elution through reverse phase C-18 column $\left(\mathrm{H}_{2} \mathrm{O} / \mathrm{MeOH}: 2 / 3\right)$ provided 1c (64 mg, 80\%) as a pale yellow syrup. 1c $(\alpha):{ }^{1} \mathrm{H}$ NMR $\left(400 \mathrm{MHz}, \mathrm{CD}_{3} \mathrm{OD}\right) \delta 8.06(\mathrm{~s}, 1 \mathrm{H}), 7.88(\mathrm{~d}, J=8.8 \mathrm{~Hz}, 1 \mathrm{H}), 6.63$ (d-like, $J=2.4 \mathrm{~Hz}, 1 \mathrm{H}), 6.53(\mathrm{dd}, J=2.8,8.8 \mathrm{~Hz}, 1 \mathrm{H}), 6.34(\mathrm{dd}$, $J=10.0,17.2 \mathrm{~Hz}, 1 \mathrm{H}), 6.27(\mathrm{dd}, J=2.0,17.2 \mathrm{~Hz}, 1 \mathrm{H}), 5.83(\mathrm{~d}$, $J=4.4 \mathrm{~Hz}, 1 \mathrm{H}, \mathrm{H}-1), 5.70(\mathrm{dd}, J=2.0,10.0 \mathrm{~Hz}, 1 \mathrm{H}), 4.57(\mathrm{dd}$, $J=3.2,12.0 \mathrm{~Hz}, 1 \mathrm{H}), 4.40(\mathrm{dd}, J=4.0,11.6 \mathrm{~Hz}, 1 \mathrm{H}), 4.25(\mathrm{~m}$, $3 \mathrm{H}), 3.85(\mathrm{~s}, 3 \mathrm{H}), 3.16(\mathrm{t}, J=4.8 \mathrm{~Hz}, 4 \mathrm{H}), 2.61(\mathrm{t}, J=4.8 \mathrm{~Hz}$, $4 \mathrm{H}), 2.34$ (s, $3 \mathrm{H}) ;{ }^{13} \mathrm{C}$ NMR $\left(100 \mathrm{MHz}, \mathrm{CD}_{3} \mathrm{OD}\right) \delta$ 168.0, 165.6, 159.5, 157.3, 151.6, 148.8, 132.1, 128.1, 123.0, 122.3, 109.3, 106.7, 101.9, 81.9 (C-1), 81.5, 73.3, 71.8, 68.2, 56.4, 55.8, 50.2, 45.6; 1c $(\beta):{ }^{1} \mathrm{H}$ NMR $\left(400 \mathrm{MHz}, \mathrm{CD}_{3} \mathrm{OD}\right) \delta 8.05(\mathrm{~s}, 1 \mathrm{H}), 7.87(\mathrm{~d}$, $J=8.4 \mathrm{~Hz}, 1 \mathrm{H}), 6.65(\mathrm{~d}-$ like, $J=2.4 \mathrm{~Hz}, 1 \mathrm{H}), 6.54(\mathrm{dd}, J=2.4$, $8.8 \mathrm{~Hz}, 1 \mathrm{H}), 6.23(\mathrm{~m}, 2 \mathrm{H}), 5.67(\mathrm{dd}, J=4.8,6.8 \mathrm{~Hz}, 1 \mathrm{H}), 5.48(\mathrm{~d}$, $J=4.4 \mathrm{~Hz}, 1 \mathrm{H}, \mathrm{H}-1), 4.58(\mathrm{dd}, J=3.6,12.0 \mathrm{~Hz}, 1 \mathrm{H}), 4.41(\mathrm{dd}$, $J=4.8,12.0 \mathrm{~Hz}, 1 \mathrm{H}), 4.24-4.14(\mathrm{~m}, 2 \mathrm{H}), 4.03(\mathrm{t}, J=4.8 \mathrm{~Hz}, 1 \mathrm{H})$, $3.84(\mathrm{~s}, 3 \mathrm{H}), 3.76(\mathrm{~m}, 2 \mathrm{H}), 3.57(\mathrm{~m}, 2 \mathrm{H}), 3.23(\mathrm{~m}, 2 \mathrm{H}), 3.00(\mathrm{~m}$, $2 \mathrm{H}$ ), 2.93 (s, $3 \mathrm{H}$ ); HRMS (ESI) m/z calcd for $\mathrm{C}_{24} \mathrm{H}_{32} \mathrm{O}_{6} \mathrm{~N}_{6} \mathrm{Cl}[\mathrm{M}$ $+\mathrm{H}]^{+}$535.2072, found 535.2087.

\section{5-O-tert-Butyldiphenylsilyl-3-0-(2,5- dichloropyrimidin-4-yl)-2-0-tert- butyldimethylsilyl- $\beta-D-$-ribofuranosyl azide 21}

To a solution of compound $19(0.86 \mathrm{~g}, 1.63 \mathrm{mmol})$ in anhydrous $\mathrm{CH}_{2} \mathrm{Cl}_{2}(25 \mathrm{~mL})$ at room temperature, was added $t \mathrm{BuOLi}(1.83 \mathrm{~g}$, $22.82 \mathrm{mmol})$ and 2,4,5-trichloropyrimidine $6(0.37 \mathrm{~mL}, 3.26$ $\mathrm{mmol}$ ). After stirring under reflux for $36 \mathrm{~h}$, the reaction mixture was diluted with saturated aqueous $\mathrm{NH}_{4} \mathrm{Cl}$, and extracted with $\mathrm{CH}_{2} \mathrm{Cl}_{2}$. The organic layer was washed with brine, dried over $\mathrm{Na}_{2} \mathrm{SO}_{4}$, and concentrated in vacuo. The residue was purified by silica gel chromatography (petroleum ether/EtOAc: $80 / 1$ ) to give $21(0.88 \mathrm{~g}, 80 \%)$ as a pale yellow syrup: ${ }^{1} \mathrm{H}$ NMR $(400 \mathrm{MHz}$, $\left.\mathrm{CDCl}_{3}\right) \delta 8.34(\mathrm{~s}, 1 \mathrm{H}), 7.71-7.67(\mathrm{~m}, 4 \mathrm{H}), 7.45-7.34(\mathrm{~m}, 6 \mathrm{H})$, $5.66(\mathrm{t}, J=4.8 \mathrm{~Hz}, 1 \mathrm{H}, \mathrm{H}-3), 5.25(\mathrm{~d}, J=3.6 \mathrm{~Hz}, 1 \mathrm{H}, \mathrm{H}-1)$, $4.40(\mathrm{dd}, J=3.6,7.6 \mathrm{~Hz}, 1 \mathrm{H}), 4.33(\mathrm{t}, J=4.4 \mathrm{~Hz}, 1 \mathrm{H}), 3.91(\mathrm{dd}$, $J=4.0,11.6 \mathrm{~Hz}, 1 \mathrm{H}), 3.84(\mathrm{dd}, J=3.6,11.6 \mathrm{~Hz}, 1 \mathrm{H}), 1.09(\mathrm{~s}, 9 \mathrm{H})$, 0.75 (s, $9 \mathrm{H}), 0.05$ (s, $3 \mathrm{H}),-0.15$ (s, $3 \mathrm{H})$; HRMS (ESI) m/z calcd for $\mathrm{C}_{31} \mathrm{H}_{42} \mathrm{O}_{4} \mathrm{~N}_{5} \mathrm{Cl}_{2} \mathrm{Si}_{2}[\mathrm{M}+\mathrm{H}]^{+}$674.2152, found 674.2155 .

\section{5-O-tert-Butyldiphenylsilyl-3-O-[5-chloro- 2-N-(2-methoxy-4-(4-methylpiperazin-1- yl)phenyl)pyrimidin-4-yl]-2-O-tert- butyldimethylsilyl- $\beta-D$-ribofuranosyl} azide 22

To a solution of compound $21(0.53 \mathrm{~g}, 0.79 \mathrm{mmol})$ and aniline derivative $8(0.70 \mathrm{~g}, 3.16 \mathrm{mmol})$ in isobutanol $(12 \mathrm{~mL})$, was added TFA $(1.47 \mathrm{~mL}, 19.75 \mathrm{mmol})$. The mixture was heated to $100^{\circ} \mathrm{C}$ and stirred for $5 \mathrm{~h}$. After cooling down to room temperature, the mixture was quenched with $\mathrm{Et}_{3} \mathrm{~N}(8 \mathrm{~mL})$ and concentrated in vacuo to give a residue, which was purified by silica gel column chromatography $\left(\mathrm{CH}_{2} \mathrm{Cl}_{2} / \mathrm{MeOH}: 30 / 1\right)$ to give $22(0.47 \mathrm{~g}, 69 \%)$ as a white powder: ${ }^{1} \mathrm{H} \mathrm{NMR}\left(400 \mathrm{MHz}, \mathrm{CDCl}_{3}\right) \delta 8.12(\mathrm{~s}, 1 \mathrm{H})$, $8.08(\mathrm{~d}, J=9.2 \mathrm{~Hz}, 1 \mathrm{H}), 7.69(\mathrm{dd}, J=1.6,7.6 \mathrm{~Hz}, 2 \mathrm{H}), 7.63$ $(\mathrm{dd}, J=1.6,8.0 \mathrm{~Hz}, 2 \mathrm{H}), 7.43-7.25(\mathrm{~m}, 6 \mathrm{H}), 6.54(\mathrm{~m}, 2 \mathrm{H}), 5.58$ $(\mathrm{dd}, J=4.4,7.2 \mathrm{~Hz}, 1 \mathrm{H}, \mathrm{H}-3), 5.29(\mathrm{~d}, J=1.6 \mathrm{~Hz}, 1 \mathrm{H}, \mathrm{H}-1)$, $4.47(\mathrm{~m}, 1 \mathrm{H}), 4.38(\mathrm{dd}, J=2.0,4.4 \mathrm{~Hz}, 1 \mathrm{H}), 4.02(\mathrm{dd}, J=2.8$, $11.6 \mathrm{~Hz}, 1 \mathrm{H}), 3.88$ (s, $3 \mathrm{H}), 3.83$ (dd, $J=3.6,12.0 \mathrm{~Hz}, 1 \mathrm{H}), 3.17$ $(\mathrm{t}, J=5.2 \mathrm{~Hz}, 4 \mathrm{H}), 2.61(\mathrm{t}, J=4.8 \mathrm{~Hz}, 4 \mathrm{H}), 2.37(\mathrm{~s}, 3 \mathrm{H}), 1.06(\mathrm{~s}$, $9 \mathrm{H}), 0.78(\mathrm{~s}, 9 \mathrm{H}),-0.07$ (s, $3 \mathrm{H}),-0.25(\mathrm{~s}, 3 \mathrm{H}) ;{ }^{13} \mathrm{C}$ NMR $(100$ $\left.\mathrm{MHz}, \mathrm{CDCl}_{3}\right) \delta 163.6,157.9,156.9,149.3,147.6,135.8,135.7$, $133.1,133.0,129.9,127.9,127.8,121.8,120.1,108.4,106.1,100.6$, 95.8, 81.6, 74.7, 74.2, 62.8, 55.8, 55.3, 50.1, 46.3, 26.9, 25.6, 19.3, 18.0, -4.9, -5.4; HRMS (ESI) $\mathrm{m} / \mathrm{z}$ calcd for $\mathrm{C}_{43} \mathrm{H}_{60} \mathrm{O}_{5} \mathrm{~N}_{8} \mathrm{ClSi}_{2}$ $[\mathrm{M}+\mathrm{H}]^{+}$859.3914, found 859.3920.

\section{5-O-tert-Butyldiphenylsilyl-3-0-[5-chloro- 2-N-(2-methoxy-4-(4-methylpiperazin-1- yl)phenyl)pyrimidin-4-yl]-2-O-tert- butyldimethylsilyl- $\alpha$-D-ribofuranosyl acrylamide 23}

A mixture of compound 22 (190 $\mathrm{mg}, 0.22 \mathrm{mmol}$ ) and $\mathrm{Pd} / \mathrm{C}$ (50 mg, 10\%) in EtOH (7 mL) was stirred under an atmosphere of $\mathrm{H}_{2}$ at room temperature for overnight. The mixture was filtered through celite, washed with EtOH and concentrated in vacuo to afford the corresponding amine for the next step without further purification. To a solution of the resulting amine in $\mathrm{CH}_{2} \mathrm{Cl}_{2}$ $(7 \mathrm{~mL})$ at room temperature, was added DCC $(69 \mathrm{mg}, 0.33$ mmol), DMAP (41 mg, $0.33 \mathrm{mmol})$, and acrylic acid $(0.061 \mathrm{~mL}$, $0.89 \mathrm{mmol})$. After stirring at room temperature for $4 \mathrm{~h}$, the mixture was concentrated in vacuo to give a residue, which was purified by silica gel column chromatography $\left(\mathrm{CH}_{2} \mathrm{Cl}_{2} / \mathrm{MeOH}\right.$ : $30 / 1)$ to afford 23 (76 mg, 39\% over two steps) as a pale yellow syrup: ${ }^{1} \mathrm{H}$ NMR $\left(400 \mathrm{MHz}, \mathrm{CDCl}_{3}\right) \delta 8.17(\mathrm{~s}, 1 \mathrm{H}), 8.09(\mathrm{~d}$, $J=8.8 \mathrm{~Hz}, 1 \mathrm{H}), 7.71(\mathrm{~m}, 4 \mathrm{H}), 7.43-7.36(\mathrm{~m}, 6 \mathrm{H}), 7.12(\mathrm{~d}$, $J=9.2 \mathrm{~Hz}, 1 \mathrm{H}), 6.53(\mathrm{~d}, J=2.4 \mathrm{~Hz}, 1 \mathrm{H}), 6.42(\mathrm{~m}, 1 \mathrm{H}), 6.36$ $(\mathrm{dd}, J=1.2,16.8 \mathrm{~Hz}, 1 \mathrm{H}), 6.14(\mathrm{dd}, J=10.4,17.2 \mathrm{~Hz}, 1 \mathrm{H}), 6.02$ (d-like, $J=4.8 \mathrm{~Hz}, 1 \mathrm{H}), 5.98(\mathrm{dd}, J=6.0,9.2 \mathrm{~Hz}, 1 \mathrm{H}), 5.70$ (dd, $J=1.2,10.4 \mathrm{~Hz}, 1 \mathrm{H}), 4.72(\mathrm{dd}, J=5.2 \mathrm{~Hz}, 1 \mathrm{H}), 4.36(\mathrm{br} \mathrm{s}, 1 \mathrm{H})$, 3.86 (m, $5 \mathrm{H}), 3.07$ (br s, $4 \mathrm{H}), 2.54$ (br s, $4 \mathrm{H}), 2.35$ (s, $3 \mathrm{H}), 1.11$ (s, $9 \mathrm{H}), 0.68(\mathrm{~s}, 9 \mathrm{H}),-0.02(\mathrm{~s}, 3 \mathrm{H}),-0.09(\mathrm{~s}, 3 \mathrm{H}) ;{ }^{13} \mathrm{C}$ NMR $(100$ $\left.\mathrm{MHz}, \mathrm{CDCl}_{3}\right) \delta 165.9,164.0,157.8,157.0,149.3,147.6,135.8$, $135.5,133.4,132.5,131.0,130.1,130.0,128.9,128.0,127.4,121.5$, $120.0,108.1,105.8,100.4,82.2,80.4,77.4,71.0,64.2,55.7,55.2$, 49.9, 46.2, 27.0, 25.4, 19.5, 17.7, -5.1, -5.3; HRMS (ESI) m/z calcd for $\mathrm{C}_{46} \mathrm{H}_{64} \mathrm{O}_{6} \mathrm{~N}_{6} \mathrm{ClSi}_{2}[\mathrm{M}+\mathrm{H}]^{+} 887.4114$, found 887.4116.

\section{3-O-[5-Chloro-2-N-(2-methoxy-4-(4- methylpiperazin-1-yl)phenyl)pyrimidin-4- yl]-2-O-tert-butyldimethylsilyl- $\alpha$-D- ribofuranosyl acrylamide 1d}

To a solution of compound $23(91 \mathrm{mg}, 0.11 \mathrm{mmol})$ in pyridine $(3 \mathrm{~mL})$ at room temperature, was added HF.pyridine $(0.19 \mathrm{~mL})$. After stirring at room temperature for overnight, the mixture was poured into saturated aqueous $\mathrm{NaHCO}_{3}$ and extracted with $\mathrm{CH}_{2} \mathrm{Cl}_{2}$. The combined organic layers were washed with brine, dried over $\mathrm{Na}_{2} \mathrm{SO}_{4}$, and concentrated in vacuo. The residue was purified by silica gel column chromatography $\left(\mathrm{CH}_{2} \mathrm{Cl}_{2} / \mathrm{MeOH}\right.$ : 
20/1) to afford $1 \mathbf{d}$ (40 mg, 68\%) as a pale yellow syrup: ${ }^{1} \mathrm{H}$ NMR $\left(400 \mathrm{MHz}, \mathrm{CDCl}_{3}\right) \delta 8.15(\mathrm{~s}, 1 \mathrm{H}), 8.02(\mathrm{~d}, J=8.4 \mathrm{~Hz}, 1 \mathrm{H}), 7.71$ (m, $4 \mathrm{H}), 7.30$ (br s, $1 \mathrm{H}), 7.06(\mathrm{~d}, J=8.4 \mathrm{~Hz}, 1 \mathrm{H}), 6.54(\mathrm{~m}, 2 \mathrm{H})$, 6.33 (d-like, $J=17.2 \mathrm{~Hz}, 1 \mathrm{H}), 6.12(\mathrm{dd}, J=10.0,16.8 \mathrm{~Hz}, 1 \mathrm{H})$, $5.90(\mathrm{dd}, J=6.0,8.4 \mathrm{~Hz}, 1 \mathrm{H}), 5.73(\mathrm{~m}, 2 \mathrm{H}), 4.51(\mathrm{t}, J=5.6 \mathrm{~Hz}$, $1 \mathrm{H}), 4.30$ (br s, $1 \mathrm{H}), 3.87$ (s, $3 \mathrm{H}), 3.82$ (d-like, $J=12.4 \mathrm{~Hz}, 1 \mathrm{H})$, 3.71 (d-like, $J=11.2 \mathrm{~Hz}, 1 \mathrm{H}), 3.18$ (br s, $4 \mathrm{H}), 2.61$ (br s, $4 \mathrm{H})$, 2.37 (s, $3 \mathrm{H}), 0.72(\mathrm{~s}, 9 \mathrm{H}),-0.02(\mathrm{~s}, 3 \mathrm{H}),-0.10(\mathrm{~s}, 3 \mathrm{H}) ;{ }^{13} \mathrm{C}$ NMR $\left(100 \mathrm{MHz}, \mathrm{CDCl}_{3}\right) \delta 166.1,163.8,157.9,157.0,149.6,147.5$, $130.9,127.7,121.9,120.5,108.6,106.1,100.8,82.1,80.6,76.3$, 70.9, 62.5, 55.8, 55.0, 49.6, 45.7, 25.5, 17.9, -5.0, -5.2; HRMS (ESI) $\mathrm{m} / \mathrm{z}$ calcd for $\mathrm{C}_{30} \mathrm{H}_{46} \mathrm{O}_{6} \mathrm{~N}_{6} \mathrm{ClSi}[\mathrm{M}+\mathrm{H}]^{+}$649.2937, found 649.2940 .

\section{Kinase Assay}

Kinases domain of EGFR WT and EGFR L858R/T790M were expressed using the Bac-to-Bac ${ }^{\mathrm{TM}}$ baculo virus expression system (Invitrogen, Carlsbad, CA, USA) and purified in NiNTA columns (QIAGEN Inc., Valencia, CA, USA). The kinase activity was evaluated with enzyme-linked immunosorbent assay (ELISA). Briefly, $20 \mu \mathrm{g} / \mathrm{mL}$ Poly (Glu, Tyr) 4:1 (Sigma, St. Louis, MO) was precoated in 96-well ELISA plates as substrate. After adding $50 \mu \mathrm{L}$ of $10 \mu \mathrm{mol} / \mathrm{L}$ ATP solution which was diluted in kinase reaction buffer ( $50 \mathrm{mM}$ HEPES pH 7.4, $20 \mathrm{mM} \mathrm{MgCl}_{2}$, $0.1 \mathrm{mM} \mathrm{MnCl} 2,0.2 \mathrm{mM} \mathrm{Na}_{3} \mathrm{VO}_{4}, 1 \mathrm{mM}$ DTT), the plate was treated with $1 \mu \mathrm{L}$ of indicated concentrations of compounds (dissolved in DMSO) per well. Experiments at each concentration were performed in duplicate. Reaction was initiated by adding tyrosine kinase diluted in kinase reaction buffer. After incubation at $37^{\circ} \mathrm{C}$ for $1 \mathrm{~h}$, the wells were washed three times with phosphate buffered saline (PBS) containing $0.1 \%$ Tween 20 (TPBS). One hundred microliters of anti-phosphotyrosine (PY99) antibody (1:1,000, Santa Cruz Biotechnology, Santa Cruz, CA) diluted in T-PBS containing $5 \mathrm{mg} / \mathrm{mL}$ BSA was added and the plate was incubated at $37^{\circ} \mathrm{C}$ for $30 \mathrm{~min}$. After the plate was washed three times, $100 \mu \mathrm{L}$ horseradish peroxidase-conjugated goat anti-mouse IgG (1:2,000, Calbiochem, SanDiego, CA) was added and the plate was incubated at $37^{\circ} \mathrm{C}$ for $30 \mathrm{~min}$. The plate was washed, added with $100 \mu \mathrm{L}$ citrate buffer (0.1 M, pH 5.5) containing $0.03 \% \mathrm{H}_{2} \mathrm{O}_{2}$. Then $2 \mathrm{mg} / \mathrm{mL} o$ phenylenediamine was added, and samples were incubated at room temperature until color emerged. The reaction was terminated immediately by adding $50 \mu \mathrm{L}$ of $2 \mathrm{M} \mathrm{H}_{2} \mathrm{SO}_{4}$. Plate was read using a multiwell spectrophotometer (VERSAmax ${ }^{\mathrm{TM}}$, Molecular Devices, Sunnyvale, CA, USA) at $492 \mathrm{~nm}$. The inhibitory rate (\%) was calculated with the formula: [1 - (A492 treated/A492 control) $] \times 100 \%$. IC $_{50}$ values were calculated from the inhibitory curves.

\section{Molecular Docking}

$\mathrm{EGFR}^{\mathrm{T} 790 \mathrm{M} / \mathrm{L} 858 \mathrm{R}}$ structure (PDB: 3IKA) was retrieved from the Protein Data Bank and covalent docking was performed with maestro (Schrödinger, Inc., version 10.2). Compound 1a was docked into the EGFR protein as an irreversible inhibitor using Covalent Docking module. The docking procedure was validated by re-docking the co-crystallized ligand WZ4002 into the ATP binding site of EGFR ${ }^{\mathrm{T} 790 \mathrm{M} / \mathrm{L} 858 \mathrm{R}}$ structure. The details of the docking workflow are listed below:

(1) Protein was prepared using the "Protein Preparation Wizard" workflow. All water molecules were removed from the structure of the complex. Hydrogen atoms and charges were added during a brief relaxation. After optimizing the hydrogen bond network, the crystal structure was minimized using the OPLS_2005 force field with the maximum root mean square deviation (RMSD) value of $0.3 \AA$.

(2) The ligand was prepared with LigPrep module in Maestro, including adding hydrogen atoms, ionizing at a $\mathrm{pH}$ range from 5.0 to 9.0 , and producing the corresponding low-energy 3D structure.

(3) Pose prediction mode of Covalent Docking module was adopted to dock the molecules into the ATP-binding site with the default parameters. The center of the grid box was defined with the intrinsic ligand and Michael addition reaction type was chosen. The top-ranking poses of molecule 1 a were retained.

\section{RESULT AND DISCUSSION}

The synthesis of 3-N-acryloyl-5-O-anilinopyrimidine ribose derivatives $\mathbf{1 a}$ and $\mathbf{1} \mathbf{b}$ commenced with 3 -amino ribose derivative 3 that can be readily prepared from D-xylose 2 in $41 \%$ yield over six steps (Scheme 1; Shie et al., 2007). Protection of the primary hydroxyl group in $\mathbf{3}$ with TBDPSCl followed by condensation with acryloyl chloride using $\mathrm{Et}_{3} \mathrm{~N}$ as base gave ribose derivative $\mathbf{4}$ in $92 \%$ yield (two steps). Treatment of $\mathbf{4}$ with HF.pyridine afforded alcohol 5 in $71 \%$ yield. When 5 was reacted with 2,4,5-trichloropyrimidine 6 in the presence of $\mathrm{K}_{2} \mathrm{CO}_{3}$ or DIPEA, almost no desired product was observed. Exhilaratingly, nucleophilic reaction of $\mathbf{5}$ with $\mathbf{6}$ employing stronger base (DBU) as promoter proceeded smoothly to provide ribose derivative 7 in excellent yield (92\%). Subjection of 7 to the known aniline derivative 8 (Han et al., 2014) under the promotion of TFA in isobutanol at $100^{\circ} \mathrm{C}$ delivered $1 \mathrm{a}$ in $69 \%$ yield. Removal of the 1,2$\mathrm{O}$-isopropylidene group in 1a with TFA in acetic acid and water at $70^{\circ} \mathrm{C}$ produced $\mathbf{1 b}$ in $83 \%$ yield.

For the synthesis of 1-N-acryloyl-5-O-anilinopyrimidine ribose derivative $\mathbf{1 c}, \beta$-ribosyl azide $\mathbf{1 0}$ was conveniently prepared from D-ribose 9 in three steps and 53\% yield according to the procedures described in the literature (Scheme 2; Bonache et al., 2009). The acetyl group in $\mathbf{1 0}$ was then replaced with TBS group to give compound $\mathbf{1 1}$ in $\mathbf{8 5 \%}$ yield. Hydrogenolysis of the azide group in 11 over $\mathrm{Pd} / \mathrm{C}$ followed by condensation with acrylic acid in the presence of DCC and DMAP afforded a mixture of ribose derivative 12 in $43 \%$ yield $\left(\alpha / \beta=1: 1 ; \alpha\right.$-anomer: $\delta_{\mathrm{H}}=6.00 \mathrm{ppm}$, $\delta_{\mathrm{C}}=81.4 \mathrm{ppm} ; \beta$-anomer: $\left.\delta_{\mathrm{H}}=5.95 \mathrm{ppm}, \delta_{\mathrm{C}}=87.2 \mathrm{ppm}\right)$, which were easily separated by silica gel column chromatography (Numao et al., 1981; Bonache et al., 2009). After removal of the TBS group in $12 \alpha$, the resulting alcohol 13 reacted with 6 in the presence of DBU to produce ribose derivative 14 in an excellent 93\% yield. TFA-promoted reaction of $\mathbf{1 4}$ with aniline $\mathbf{8}$ led to $\mathbf{1 5}$ in $70 \%$ yield as a mixture of $\alpha / \beta$ anomers probably arising from the anomerization of the $1-N$-acryloyl ribose derivative under 

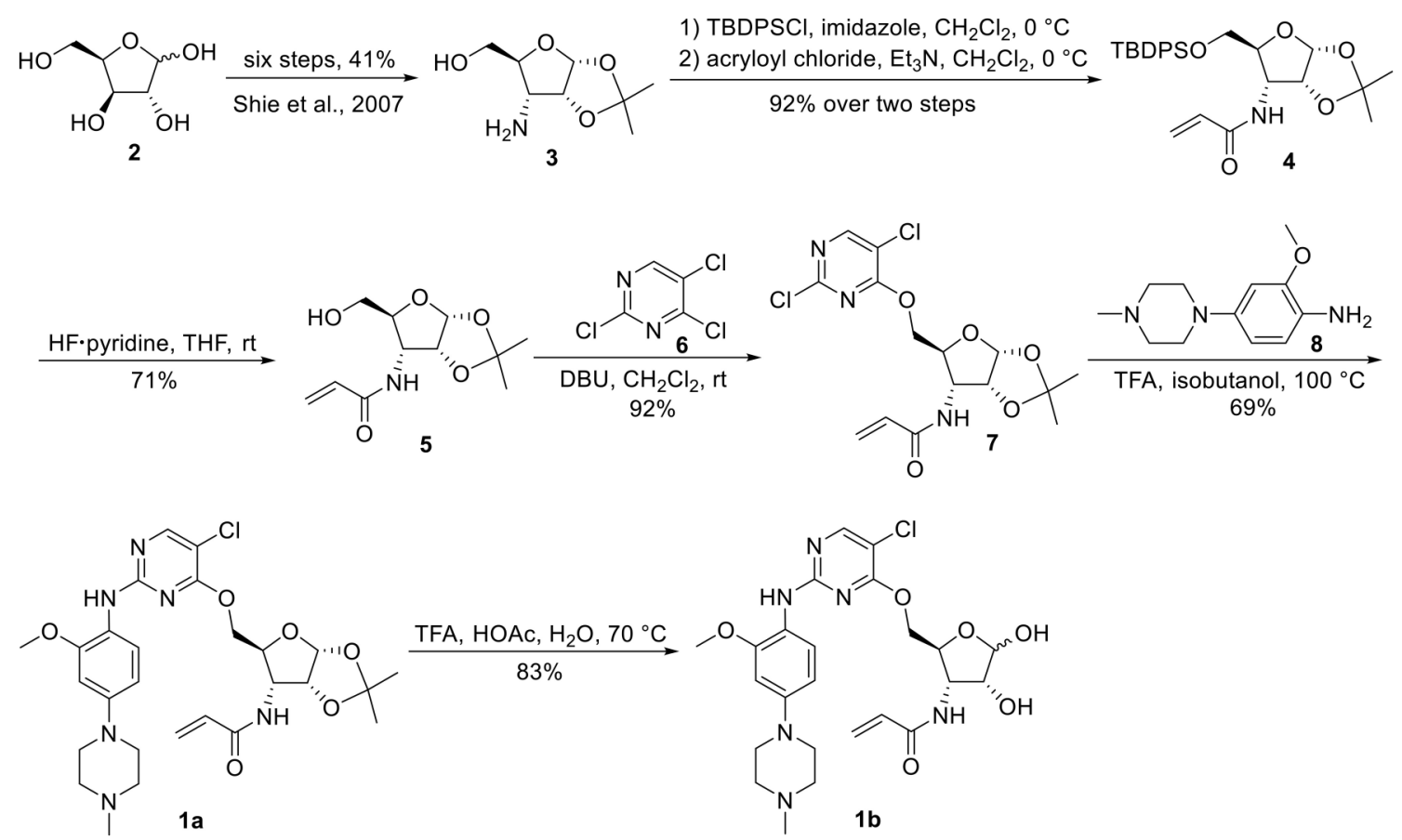

SCHEME $\mathbf{1}$ | Synthesis of 3-N-acryloyl-5-O-anilinopyrimidine ribose derivatives $\mathbf{1 a}$ and $\mathbf{1 b}$.

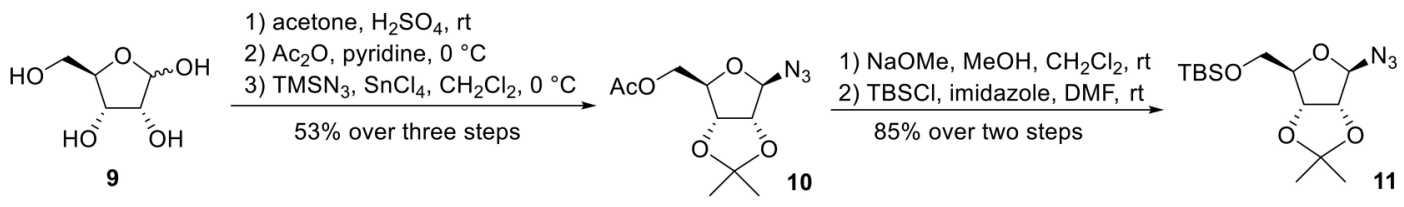

1) $\mathrm{H}_{2}, \mathrm{Pd} / \mathrm{C}, \mathrm{EtOH}, \mathrm{rt}$

2) acrylic acid, DCC,

DMAP, $\mathrm{CH}_{2} \mathrm{Cl}_{2}, \mathrm{rt}$

$43 \%$ over two steps

$\alpha: \beta=1: 1$<smiles>C=CC(=O)N[C@H]1O[C@H](CO[AsH3])[C@H]2OC(C)(C)O[C@H]12</smiles>

TBSO $\frac{\text { HF.pyridine, THF, rt }}{85 \%}$ $12 \alpha$
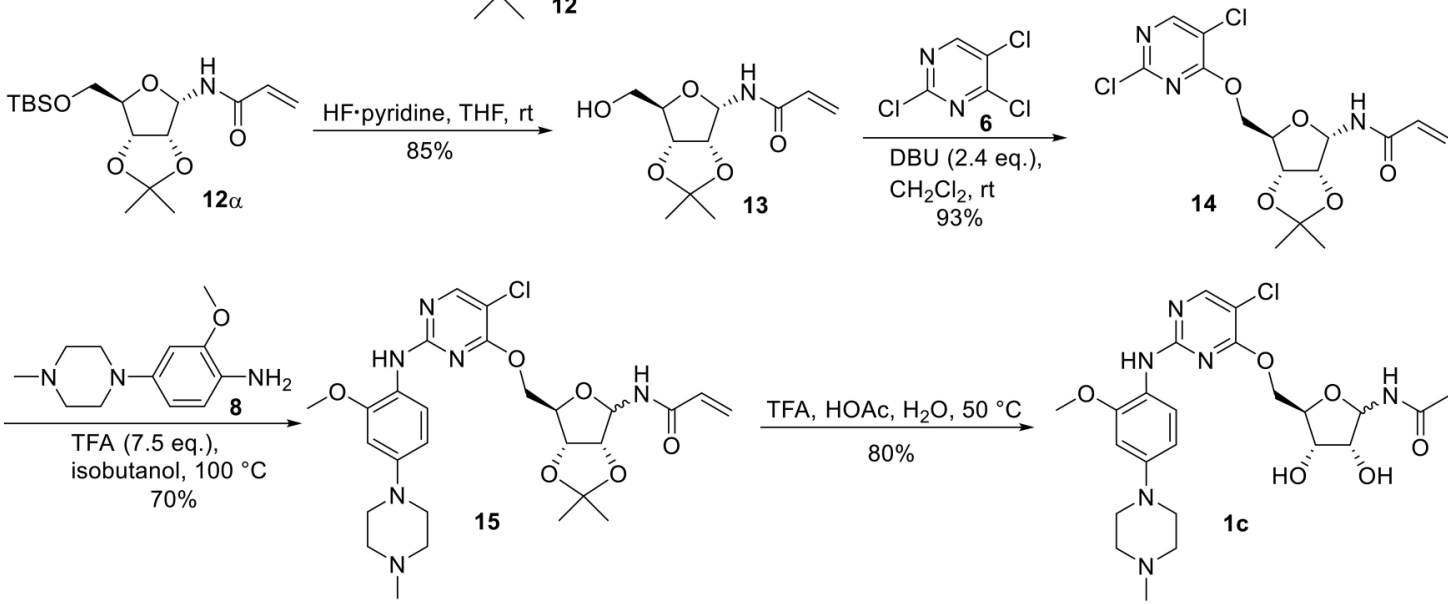

TFA, $\mathrm{HOAC}, \mathrm{H}_{2} \mathrm{O}, 50^{\circ} \mathrm{C}$

$80 \%$

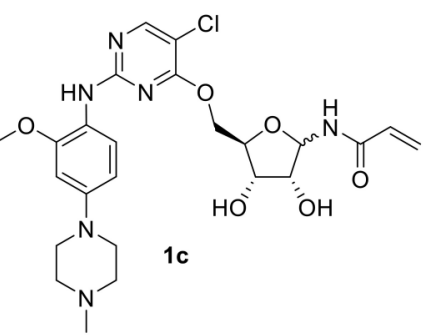

SCHEME 2 | Synthesis of 1-N-acryloyl-5-O-anilinopyrimidine ribose derivative 1c. 
strong acidic conditions (Boschelli et al., 1989). Finally, acidic cleavage of the isopropylidene group of $\mathbf{1 5}$ in the mixture of TFA/HOAc/water provided $1 \mathrm{c}$ in $80 \%$ yield.

Synthetic work toward 1-N-acryloyl-3-O-anilinopyrimidine ribose derivative 1d started from replacement of the 2,3isopropylidene group of azide $\mathbf{1 0}$ with 2,3-orthoester group by treatment with TFA and subsequent protection with triethyl orthoacetate under the catalysis of TsOH. $\mathrm{H}_{2} \mathrm{O}$, affording azide $\mathbf{1 6}$ in $76 \%$ yield over two steps (Scheme 3). Substitution of the acetyl group in $\mathbf{1 6}$ with TBDPS group and subsequent acidic cleavage of the orthoester group led to an inseparable mixture of 2-acetyl and 3 -acetyl ribose derivatives 17 and 18 (77\% yield over three steps). Treatment of the mixture of $\mathbf{1 7}$ and $\mathbf{1 8}$ with TBSCl followed by removal of the acetyl groups gave alcohols 19 and 20 in $83 \%$ yield, allowing for the separation of 3-hydroxyl ribose derivative 19 from 2-hydroxyl ribose derivative $20(\mathbf{1 9 : 2 0}=3: 2)$. Nucleophilic

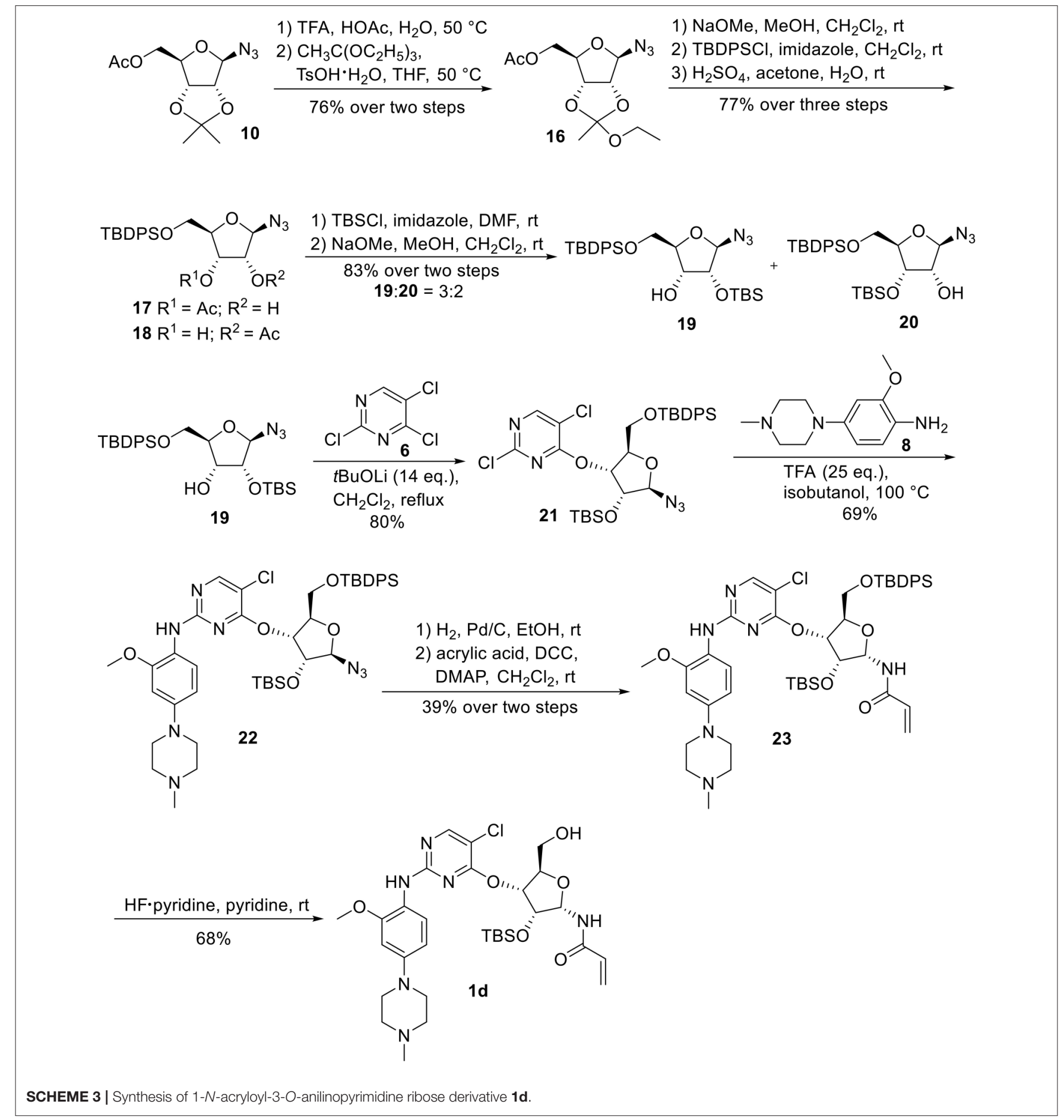


attack of 19 on 6 required stronger basic conditions to promote the reaction due to the steric hindrance of the silyl groups on 19. As such, excess $t \mathrm{BuOLi}$ in dichloromethane under reflux was employed for this conversion, providing ribose derivative $\mathbf{2 1}$ in $80 \%$ yield. TFA-promoted coupling of $\mathbf{2 1}$ with aniline $\mathbf{8}$ generated ribose derivative 22 (69\%), which was then subjected to hydrogenolysis over $\mathrm{Pd} / \mathrm{C}$ and subsequent condensation with acrylic acid to afford ribose derivative $\mathbf{2 3}$ as single anomer in moderate yield (39\% over two steps). Exposure of $\mathbf{2 3}$ to HF.pyridine in pyridine resulted in cleavage of the TBDPS group without affecting the TBS group, providing 1 d in $68 \%$ yield.

To determine whether the Michael acceptor played a significant role in the inhibitory activity of ribosemodified pyrimidine derivatives against EGFR tyrosine kinase, 1-azide-5-O-anilinopyrimidine ribose derivative $\mathbf{2 4}$, 1-azide-3-O-anilinopyrimidine ribose derivative 25 , and 5-Oanilinopyrimidine ribose derivative $\mathbf{2 6}$ were readily synthesized following the similar procedures described for 1a-1d (Table 1; see Supplementary Material for details).

As shown in Table $\mathbf{1}$, compounds $\mathbf{1 a}$ and $\mathbf{1 b}$ containing 3-N-acryloyl-5-O-anilinopyrimidine ribosyl moiety potently inhibited EGFR L858R/T790M mutant with $\mathrm{IC}_{50}$ values of 0.62 and $2.64 \mu \mathrm{M}$, revealing specific inhibitory activity for EGFR L858R/T790M over WT EGFR, although they are not comparable to the positive controls osimertinib $\left(\mathrm{IC}_{50}=1.5 \mathrm{nM}\right.$ for EGFR L858R/T790M) and afatinib ( $\mathrm{IC}_{50}=3.7 \mathrm{nM}$ for EGFR L858R/T790M). In contrast, other compounds (1c, 1d, and 24-26) bearing 5-O-anilinopyrimidine ribosyl moiety, $1-\mathrm{N}$-acryloyl-5-O-anilinopyrimidine ribosyl moiety, $1-\mathrm{N}$ acryloyl-3-O-anilinopyrimidine ribosyl moiety, or their 1-azide counterparts, showed no inhibitory activities against EGFR tyrosine kinases.

In order to better understand the mechanism of this type of compounds binding to EGFR T790M, molecular docking was adopted to predict the binding mode of the representative compound 1a. The docking procedure was validated in advance by re-docking the co-crystallized ligand WZ4002 (Zhou et al., 2009) into the ATP binding site of EGFR L858R/T790M structure (PDB ID: 3IKA). The root mean square deviation (RMSD) between the crystallographic and docked conformation of WZ4002 is $0.57 \AA$ (Figure S1), demonstrating that the present docking procedure was feasible in generating the binding conformation accurately. As expected based upon co-crystal structure of the anilinopyrimidine-derived inhibitor WZ4002, the anilinopyrimidine core of compound 1a forms a bidentate hydrogen bonding interaction with the "hinge" residue Met793 (Figure 3). The chlorine substituent on the pyrimidine ring could form hydrophobic contact with the mutant gatekeeper residue, Met790. The aniline ring is oriented to form hydrophobic interactions with Leu792 and Pro794 in the hinge region. Moreover, the acrylamide group attached to the sugar ring of compound la could form a covalent bond with Cys797 to achieve irreversible binding. The sugar ring acts like a linker to tune the orientation of the electrophilic acrylamide moiety that can covalently alkylate the conserved cysteine residue Cys797. For the 1,2-O-isopropylidene moiety in compound $\mathbf{1 a}$, it could form favorable vdW interactions with residues ARG841, ASN842,
TABLE 1 | In vitro inhibitory activities of ribose-modified pyrimidine derivatives 1a-1d and 24-26 against EGFR tyrosine kinase.<smiles>[R]c1nc(Nc2ccc(N3CCN(C)CC3)cc2OC)ncc1Cl</smiles>
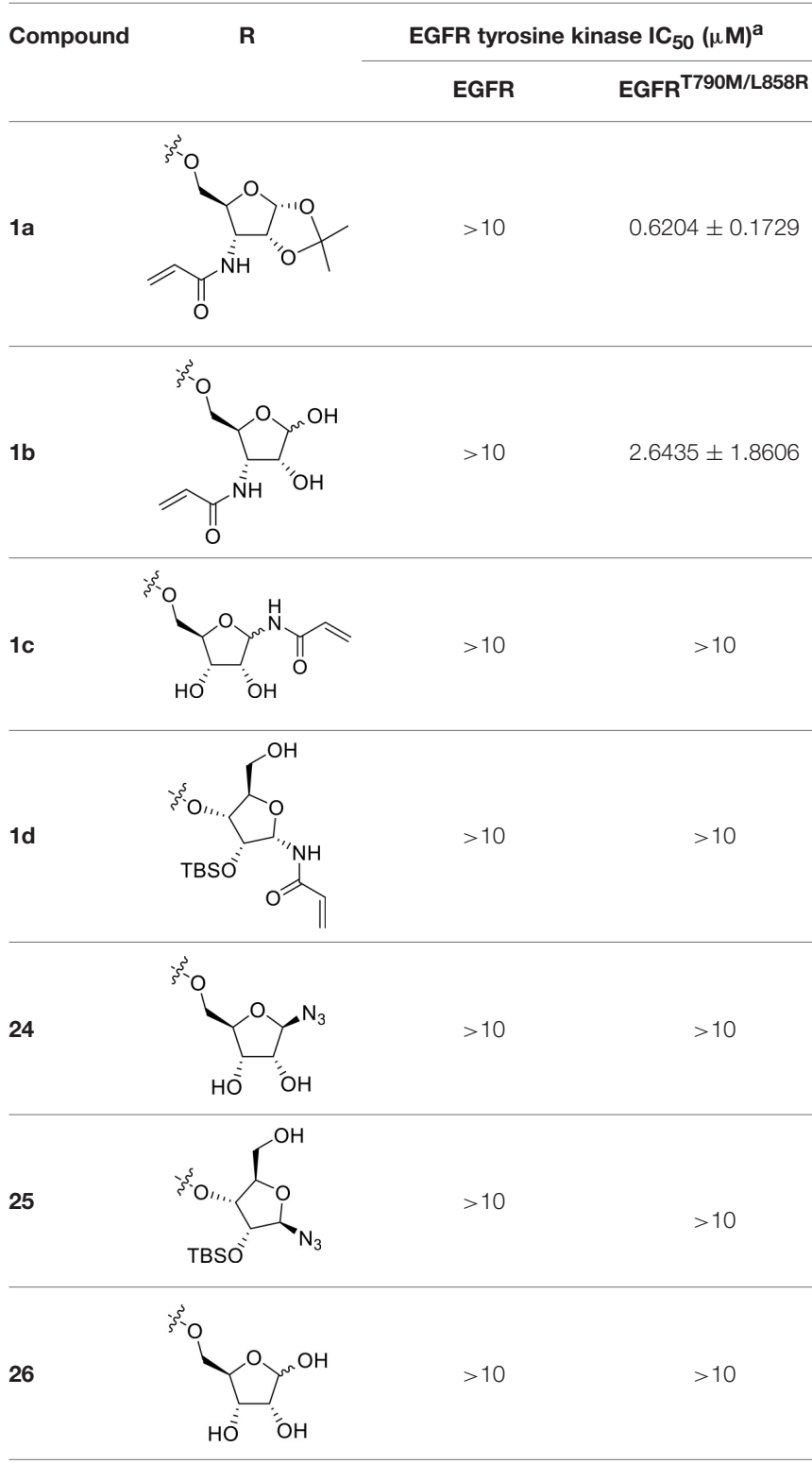

\begin{tabular}{lcc}
\hline Osimertinib $^{b}$ & $0.1586 \pm 0.0428$ & $0.0015 \pm 0.0001$ \\
\hline Afatinib $^{b}$ & $0.00697 \pm 0.00052$ & $0.00374 \pm 0.00035$
\end{tabular}

a Kinase activity assays were examined by using the ELISA-based EGFR-TK assay. Data are averages of at least two independent determinations and reported as the mean $\pm S D$ (standard deviation).

${ }^{b}$ Reported data. 


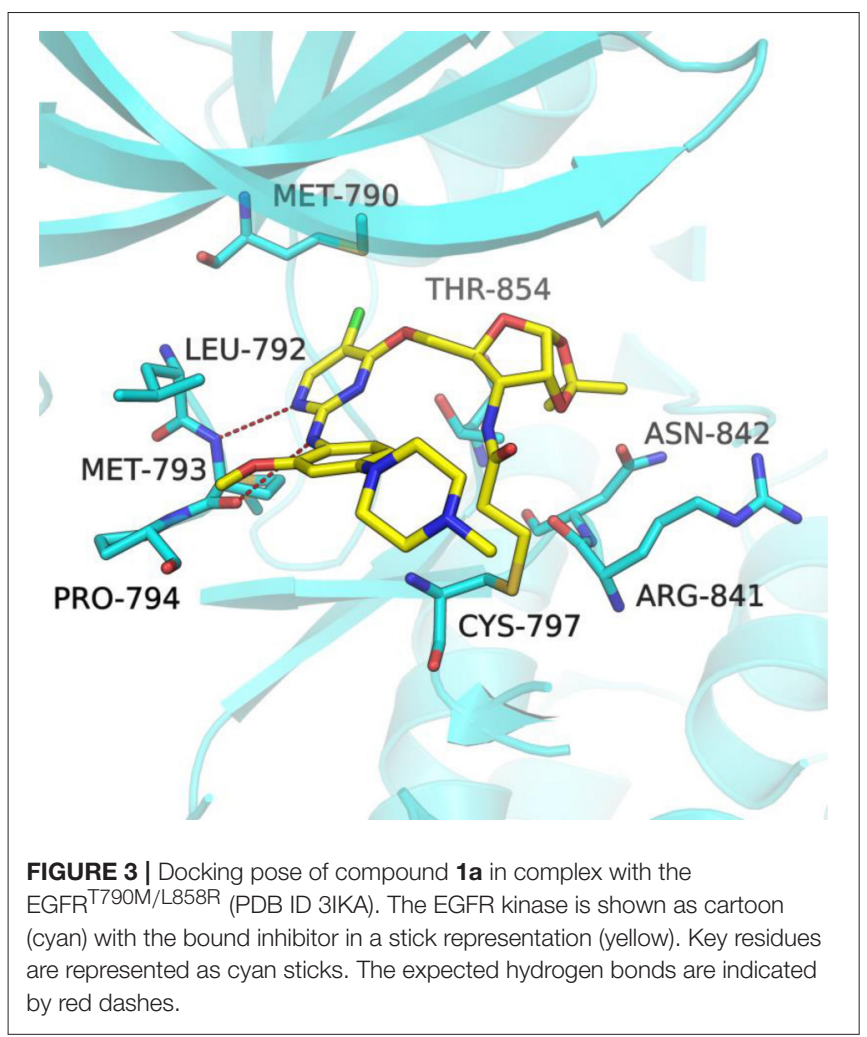

and Thr854. Therefore, compound $\mathbf{1 b}$ without that protecting group on the sugar ring, displayed less potent bioactivity against EGFR T790M/L858R compared with compound 1a. Lacking of the Michael receptor, compounds 24-26 are unable to form covalent bond with Cys797 and thus displayed sharply decreased inhibitory activity against EGFR T790M/L858R. Compound 1c displayed no inhibitory activity of EGFR probably because of the long distance between the Michael receptor and Cys797. Although compound 1d also has an acrylamide group attached to the sugar ring, it showed no inhibitory activity probably due to the conformational alteration of compound $\mathbf{1 d}$ caused by the TBS protecting group. Briefly, it could be concluded that the distance between the Michael receptor and the pyrimidine scaffold has a significant effect on the inhibitory potency of this type of compounds. Employing the ribosyl moiety as a chiral building

\section{REFERENCES}

Balak, M. N., Gong, Y., Riely, G. J., Somwar, R., Li, A. R., Zakowski, M. F., et al. (2006). Novel D761Y and common secondary T790M mutations in epidermal growth factor receptor-mutant lung adenocarcinomas with acquired resistance to kinase inhibitors. Clin. Cancer Res. 12, 6494-6501. doi: 10.1158/1078-0432.CCR-06-1570

Bonache, M. A., Nuti, F., Le Chevalier Isaad, A., Real-Fernandez, F., Chelli, M., Rovero, P., et al. (2009). Synthesis of new ribosylated Asn building blocks as useful tools for glycopeptide and glycoprotein synthesis. Tetrahedron Lett. 50, 4151-4153. doi: 10.1016/j.tetlet.2009.04.124

Boschelli, D. H., Powell, D., Sharky, V., and Semmelhack, M. F. (1989). An improved synthesis of glycinamide ribonucleotide. block for modulating the distance between the Michael receptor and the pyrimidine scaffold could pave a new avenue for future design of EGFR inhibitors against EGFR mutants.

\section{CONCLUSION}

In summary, we have described a DBU- or $t \mathrm{BuOLi}$-promoted coupling of ribosyl alcohols with 2,4,5-trichloropyrimidine as key step for the synthesis of a series of ribose-modified anilinopyrimidine derivatives as EGFR TKIs. Preliminary biological evaluation indicated that compound 1a displayed potent inhibitory activity against EGFR L858R/T790M with an $\mathrm{IC}_{50}$ value of $0.62 \mu \mathrm{M}$, and good selectivity for EGFR L858R/T790M over WT EGFR. Molecular docking studies revealed that the inhibitory activities of this type of compounds are largely influenced by the distance between the Michael receptor and the pyrimidine scaffold. As a novel type of EGFR inhibitor, the ribose-modified anilinopyrimidine derivative 1a might be used as a promising lead compound for further development of selective EGFR inhibitors to overcome EGFR L858R/T790M resistance mutation.

\section{AUTHOR CONTRIBUTIONS}

YY and YX designed and guided this study. $\mathrm{XH}$ conducted the chemical synthesis. YT, LT, LZ, and HX performed the kinase activity assays. DW, XW, and SL performed the molecular docking studies. XH, YY, and YX analyzed the data and wrote the manuscript with input from all authors.

\section{ACKNOWLEDGMENTS}

Financial support from the National Thousand Young Talents Program (YC0130518, YC0140103), the Shanghai Committee of Science and Technology (14431902100), and the Shanghai Pujiang Program (15PJ1401500), is gratefully acknowledged.

\section{SUPPLEMENTARY MATERIAL}

The Supplementary Material for this article can be found online at: https://www.frontiersin.org/articles/10.3389/fchem. 2017.00101/full\#supplementary-material
Tetrahedron Lett. 30, 1599-1600. doi: 10.1016/S0040-4039(00)99 530-3

Castellanos, E. H., and Horn, L. (2015). Generations of epidermal growth factor receptor tyrosine kinase inhibitors: perils and progress. Curr. Treat. Options Oncol. 16, 51. doi: 10.1007/s11864-015-0365-1

Cheng, H., Nair, S. K., and Murray, B. W. (2016). Recent progress on third generation covalent EGFR inhibitors. Bioorg. Med. Chem. Lett. 26, 1861-1868. doi: 10.1016/j.bmcl.2016.02.067

Cohen, M. H., Johnson, J. R., Chen, Y. F., Sridhara, R., and Pazdur, R. (2005). FDA drug approval summary: erlotinib (Tarcevaß) tablets. Oncologist 10, 461-466. doi: 10.1634/theoncologist.10-7-461

Cross, D. A., Ashton, S. E., Ghiorghiu, S., Eberlein, C., Nebhan, C. A., Spitzler, P. J., et al. (2014). AZD9291, an irreversible EGFR TKI, overcomes T790M-mediated 
resistance to EGFR inhibitors in lung cancer. Cancer Discov. 4, 1046-1061. doi: 10.1158/2159-8290.CD-14-0337

De Luca, A., Carotenuto, A., Rachiglio, A., Gallo, M., Maiello, M. R., Aldinucci, D., et al. (2008). The role of the EGFR signaling in tumor microenvironment. J. Cell. Physiol. 214, 559-567. doi: 10.1002/jcp.21260

Dungo, R. T., and Keating, G. M. (2013). Afatinib: first global approval. Drugs 73, 1503-1515. doi: 10.1007/s40265-013-0111-6

Eberlein, C. A., Stetson, D., Markovets, A. A., Al-Kadhimi, K. J., Lai, Z., Fisher, P. R., et al. (2015). Acquired resistance to the mutantselective EGFR inhibitor AZD9291 is associated with increased dependence on RAS signaling in preclinical models. Cancer Res. 75, 2489-2500. doi: 10.1158/0008-5472.CAN-14-3167

Finlay, M. R., Anderton, M., Ashton, S., Ballard, P., Bethel, P. A., Box, M. R., et al. (2014). Discovery of a potent and selective EGFR inhibitor (AZD9291) of both sensitizing and T790M resistance mutations that spares the wild type form of the receptor. J. Med. Chem. 57, 8249-8267. doi: 10.1021/jm500973a

Gray, J., and Haura, E. (2014). Update on third-generation EGFR tyrosine kinase inhibitors. Transl. Lung Cancer Res. 3, 360-362. doi: 10.3978/j.issn.2218-6751.2014.09.08

Grünwald, V., and Hidalgo, M. (2003). Developing inhibitors of the epidermal growth factor receptor for cancer treatment. J. Natl. Cancer Inst. 95, 851-867. doi: 10.1093/jnci/95.12.851

Gschwind, A., Fischer, O. M., and Ullrich, A. (2004). The discovery of receptor tyrosine kinases: targets for cancer therapy. Nat. Rev. Cancer 4, 361-370. doi: $10.1038 / \mathrm{nrc1} 360$

Günther, M., Juchum, M., Kelter, G., Fiebig, H., and Laufer, S. (2016). Lung cancer: EGFR inhibitors with low nanomolar activity against a therapy-resistant L858R/T790M/C797S mutant. Angew. Chem. Int. Ed. 55, 10890-10894. doi: 10.1002/anie.201603736

Günther, M., Lategahn, J., Juchum, M., Döring, E., Keul, M., Tumbrink, H. L., et al. (2017). Trisubstituted pyridinylimidazoles as potent inhibitors of the clinically resistant L858R/T790M/C797S EGFR mutant: targeting of both hydrophobic regions and the phosphate binding site. J. Med. Chem. 60, 5613-5637. doi: 10.1021/acs.jmedchem.7b00316

Han, C., Wan, L., Ji, H., Ding, K., Huang, Z., Lai, Y., et al. (2014). Synthesis and evaluation of 2-anilinopyrimidines bearing 3-aminopropamides as potential epidermal growth factor receptor inhibitors. Eur. J. Med. Chem. 77, 75-83. doi: 10.1016/j.ejmech.2014.02.032

Harrington, K. J., El-Hariry, I. A., Holford, C. S., Lusinchi, A., Nutting, C. M., Rosine, D., et al. (2009). Phase I study of lapatinib in combination with chemoradiation in patients with locally advanced squamous cell carcinoma of the head and neck. J. Clin. Oncol. 27, 1100-1107. doi: 10.1200/JCO.2008.17.5349

Huang, S. M., and Harari, P. M. (1999). Epidermal growth factor receptor inhibition in cancer therapy: biology, rationale and preliminary clinical results. Invest. New Drugs 17, 259-269. doi: 10.1023/A:1006384521198

Jia, Y., Yun, C. H., Park, E., Ercan, D., Manuia, M., Juarez, J., et al. (2016). Overcoming $\operatorname{EGFR}(\mathrm{T} 790 \mathrm{M})$ and $\operatorname{EGFR}(\mathrm{C} 797 \mathrm{~S})$ resistance with mutantselective allosteric inhibitors. Nature 534, 129-132. doi: 10.1038/nature17960

Juchum, M., Günther, M., Döring, E., Sievers-Engler, A., Lämmerhofer, M., and Laufer, S. (2017). Trisubstituted imidazoles with a rigidized hinge binding motif act as single digit nM inhibitors of clinically relevant EGFR L858R/T790M and L858R/T790M/C797S mutants: an example of target hopping. J. Med. Chem. 60, 4636-4656. doi: 10.1021/acs.jmedchem.7b00178

Kris, M. G., Natale, R. B., Herbst, R. S., Lynch, T. J., Prager, D., Belani, C. P., et al. (2003). Efficacy of gefitinib, an inhibitor of the epidermal growth factor receptor tyrosine kinase, in symptomatic patients with non-small cell lung cancer. JAMA 290, 2149-2158. doi: 10.1001/jama.290.16.2149

Moore, M. J., Goldstein, D., Hamm, J., Figer, A., Hecht, J. R., Gallinger, S., et al. (2007). Erlotinib plus gemcitabine compared with gemcitabine alone in patients with advanced pancreatic cancer: a phase III trial of the national cancer institute of Canada clinical trials group. J. Clin. Oncol. 25, 1960-1966. doi: 10.1200/JCO.2006.07.9525

Niederst, M. J., Hu, H., Mulvey, H. E., Lockerman, E. L., Garcia, A. R., Piotrowska, Z., et al. (2015). The allelic context of the C797S mutation acquired upon treatment with third generation EGFR inhibitors impacts sensitivity to subsequent treatment strategies. Clin. Cancer Res. 21, 3924-3933. doi: 10.1158/1078-0432.CCR-15-0560

Normanno, N., Bianco, C., De Luca, A., Maiello, M. R., and Salomon, D. S. (2003). Target-based agents against ErbB receptors and their ligands: a novel approach to cancer treatment. Endocr. Relat. Cancer 10, 1-21. doi: 10.1677/erc.0.0100001

Numao, N., Hemmi, H., Naujokaitis, S. A., Rabinovitz, M., and Beisler, J. A. (1981). Showdomycin analogues: synthesis and antitumor evaluation. J. Med. Chem. 24, 515-520. doi: 10.1021/jm00137a008

Ozvegy-Laczka, C., Cserepes, J., Elkind, N. B., and Sarkadi, B. (2005). Tyrosine kinase inhibitor resistance in cancer: role of ABC multidrug transporters. Drug Resist. Updates 8, 15-26. doi: 10.1016/j.drup.2005.02.002

Pao, W., and Chmielecki, J. (2010). Rational, biologically based treatment of EGFR-mutant non-small-cell lung cancer. Nat. Rev. Cancer 10, 760-774. doi: 10.1038/nrc2947

Park, H., Jung, H. Y., Mah, S., and Hong, S. (2017). Discovery of EGF receptor inhibitors that are selective for the $\mathrm{d} 746-750 / \mathrm{T} 790 \mathrm{M} / \mathrm{C} 797 \mathrm{~S}$ mutant through structure-based de novo design. Angew. Chem. 56, 7634-7638. doi: 10.1002/anie.201703389

Piotrowska, Z., Niederst, M. J., Karlovich, C. A., Wakelee, H. A., Neal, J. W., Mino-Kenudson, M., et al. (2015). Heterogeneity underlies the emergence of EGFRT790 wild-type clones following treatment of T790M-positive cancers with a third-generation EGFR inhibitor. Cancer Discov. 5, 713-722. doi: 10.1158/2159-8290.CD-15-0399

Shie, J. J., Fang, J. M., Wang, S. Y., Tsai, K. C., Cheng, Y. S. E., Yang, A. S., et al. (2007). Synthesis of tamiflu and its phosphonate congeners possessing potent anti-influenza activity. J. Am. Chem. Soc. 129, 11892-11893. doi: $10.1021 /$ ja073992i

Steuer, C. E., Khuri, F. R., and Ramalingam, S. S. (2015). The next generation of epidermal growth factor receptor tyrosine kinase inhibitors in the treatment of lung cancer. Cancer 121, E1-E6. doi: 10.1002/cncr.29139

Thress, K. S., Paweletz, C. P., Felip, E., Cho, B. C., Stetson, D., Dougherty, B., et al. (2015). Acquired EGFR C797S mutation mediates resistance to AZD9291 in non-small cell lung cancer harboring EGFR T790M. Nat. Med. 21, 560-562. doi: $10.1038 / \mathrm{nm} .3854$

Traxler, P., and Furet, P. (1999). Strategies toward the design of novel and selective protein tyrosine kinase inhibitors. Pharmacol. Ther. 82, 195-206. doi: 10.1016/s0163-7258(98)00044-8

Walter, A. O., Sjin, R. T., Haringsma, H. J., Ohashi, K., Sun, J., Lee, K., et al. (2013). Discovery of a mutant-selective covalent inhibitor of EGFR that overcomes T790M-mediated resistance in NSCLC. Cancer Discov. 3, 1404-1415. doi: 10.1158/2159-8290.CD-13-0314

Zhou, W., Ercan, D., Chen, L., Yun, C. H., Li, D., Capelletti, M., et al. (2009). Novel mutant-selective EGFR kinase inhibitors against EGFR T790M. Nature 462, 1070-1074. doi: 10.1038/nature08622

Conflict of Interest Statement: The authors declare that the research was conducted in the absence of any commercial or financial relationships that could be construed as a potential conflict of interest.

Copyright (c) $2017 \mathrm{Hu}$, Wang, Tong, Tong, Wang, Zhu, Xie, Li, Yang and Xu. This is an open-access article distributed under the terms of the Creative Commons Attribution License (CC BY). The use, distribution or reproduction in other forums is permitted, provided the original author(s) or licensor are credited and that the original publication in this journal is cited, in accordance with accepted academic practice. No use, distribution or reproduction is permitted which does not comply with these terms. 